\title{
Nemaline myopathy
}

INSERM

\section{Source}

INSERM. (1999). Orphanet: an online rare disease and orphan drug data base. Nemaline myopathy. ORPHA:607

Nemaline myopathy (NM) encompasses a large spectrum of myopathies characterized by hypotonia, weakness and depressed or absent deep tendon reflexes, with pathologic evidence of nemaline bodies (rods) on muscle biopsy. 